\title{
QUIZ \\ WHAT IS YOUR DIAGNOSIS?
}

11-year-old boy diagnosed with unspecific malabsorption syndrome, IgA deficiency and unspecific myopathy was admitted to the hospital with several months' history of recurrent diarrhoea and symptoms of functional intestinal disturbances suggestive of partial intestinal obstruction. The symptoms worsened during last three weeks. The boy complained about colicky abdominal pain.

The boy was cachectic, his body mass as well as height were below $3^{\text {rd }}$ percentile. On physical examination his abdomen was distended, but bowel sounds were easily heard. Ultrasound and computed tomography revealed first small intestinal loop distended up to $10 \mathrm{~cm}$ on a distance of $15 \mathrm{~cm}$. Sigmoid colon was slightly extended, as well. Blood tests were as follow: $\mathrm{Hb}=13.2 \mathrm{~g} \%, \mathrm{Ht}=39 \%, \mathrm{PTL}=241000 \mu \mathrm{l} / \mathrm{l}, \mathrm{RBC}$ $=4,7 \mathrm{mln} / \mu \mathrm{l}, \mathrm{WBC}=6000 / \mu \mathrm{l}, \mathrm{CRP}<5 \mathrm{mg} / \mathrm{l}(0-$ $10)$, electrolytes and glucose level within normal lim-

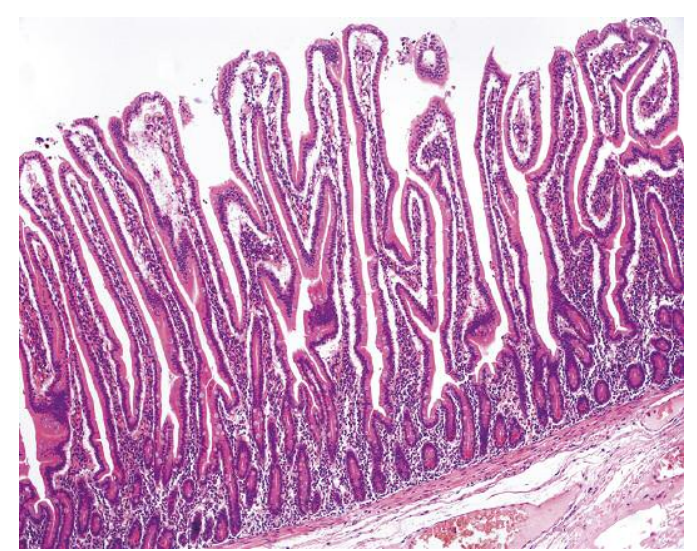

Fig. 1.

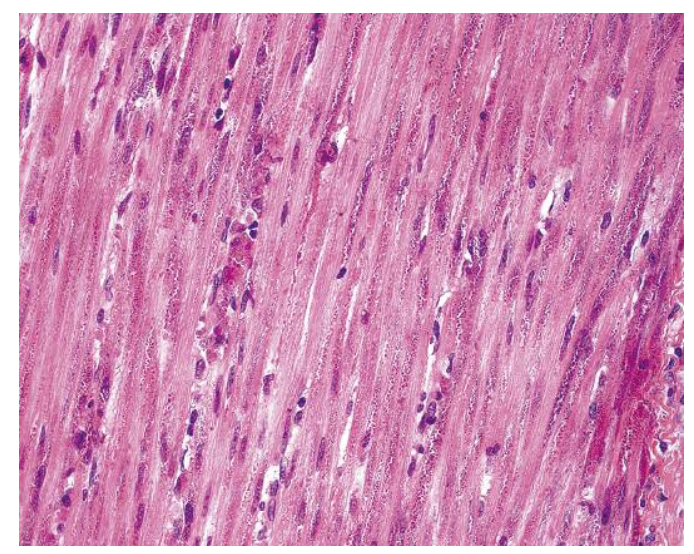

Fig. 3. its, AspAt $157 \mathrm{U} / \mathrm{l}(5-40)$, Alat $161 \mathrm{U} / \mathrm{l}(7-56)$, LDH $2113 \mathrm{U} / \mathrm{l}$ (300-620). Total protein level $5.4 \mathrm{~g} \%$ (6-8), albumin level $3.04 \mathrm{~g} / \mathrm{dl}$.

The child was operated: laparotomy revealed the first jejunal loop with homogenous blackish discoloration of the surface. Resection of $18 \mathrm{~cm}$ long segment of small intestine was done. The material was sent to the histological examination.

The boy was born on time with signs of exenteration (evisceration). He was operated in the first day of life. Three weeks later the child was re-operated because of small bowel obstruction; Bishop-Coop fistula was done. Four weeks later intestinal continuity was restored.

The histological pictures of intestinal wall and small mesenteric lymph node are shown on Figs. 1-4.

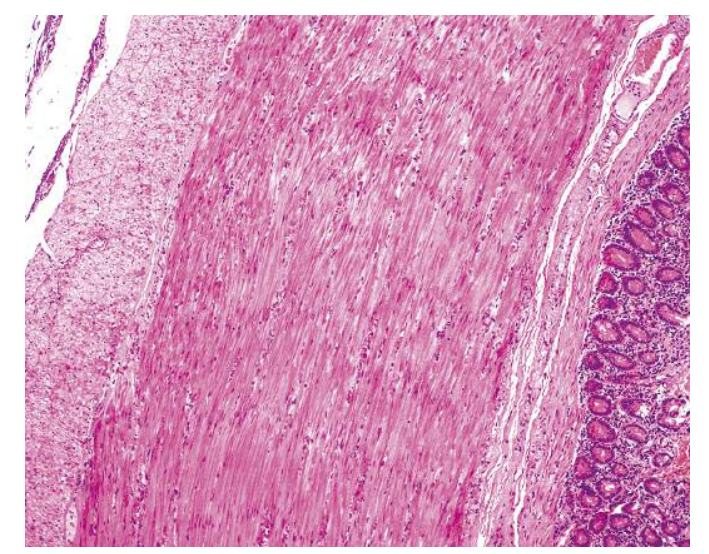

Fig. 2.

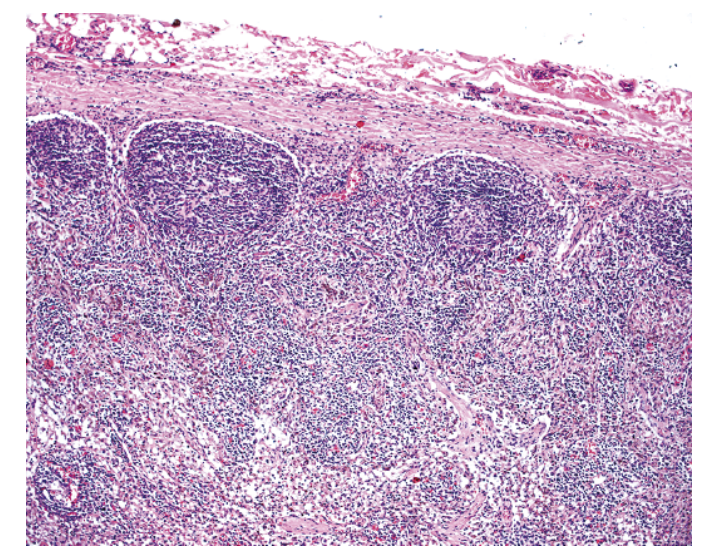

Fig. 4.

Sergiusz Demczuk ${ }^{1}$, Magdalena Białas ${ }^{1}$, Grzegorz Dyduch $^{1}$, Grażyna Drabik ${ }^{2}$, Małgorzata Chrupek ${ }^{3}$, Krzysztof Okoń $^{1}$

${ }^{1}$ Chair and Department of Pathomorphology, UJCM, Krakow; ${ }^{2}$ Department of Pathomorphology, University Children's Hospital in Krakow; ${ }^{3}$ Clinic of Children's Surgery, University Children's Hospital in Krakow

Answers should be sent to the Editorial Office by 31.08.2013. The correct answer will be announced in the next issue of the Polish Journal of Patbology. All participants with the highest number of correct answers to the quizzes published in vol. 64 ( 4 issues) will be entered into the prize draw for a book. 